\title{
Metanoia as a Response to Philosophy's Death: From Injustice to Conversion
}

Jonathan Ray Villacorta

\begin{abstract}
When the fate of the Japanese people has been decided at the end of the war, the Japanese intellectuals cannot feign a naïve stance of innocence that would have mitigated pursed lips, silent pens and empty sheets of paper. And when some of them did take this recourse, or worse, tried to revise their earlier positions with regard to the Japanese' involvement in the World War by tampering on their published works, Hajime Tanabe took the road less traveled and confronted the issue of flawed scientific philosophical position head-on; his is a genuine attempt at self-criticism that would put to question every inveterate beliefs one has held at the expense of an openness to a reality that is neither pre-given nor statically perfect. This paper, then, will be a reflection on Tanabe's suggestion on what we should or could do if rationality has become pathological, if thinking can no longer contain the irrational, and if at the demise of philosophy, nothing remains but the haunting gossamer of injustice's debris crying for recognition, demanding for an apology.
\end{abstract}

Key words: Hajime Tanabe, metanoia, zange, metanoetics

\section{Prologue}

$\mathrm{W}$

hen the fate of the Japanese people was decided at the end of the Second World War, the Japanese intellectuals could not feign a naïve stance of innocence that would have mitigated pursed lips, silent pens and empty sheets of paper. And when some of them did take this recourse, or worse, tried to revise their earlier positions with regard to the Japanese' involvement in the War by tampering on their published works, Hajime Tanabe took the road less traveled and confronted the issue of flawed scientific philosophical position head-on. ${ }^{1}$ The easy path of preserving through

${ }^{1}$ James Heisig gave a picturesque portrait of this event. He says, “After the surrender of 1945, many of Japan's writers broke their pens in shame. Others reupholstered their memory to find a consistency in their ideas that never was there. Some even doctored their collected works to hide the stains." Philosophers of Notbingness: An Essay on the Kyoto School (Honolulu: University of Hawaii Press, 2001), 155. This particular portrayal situates the role of Hajime Tanabe's Philosophy of Metanoetics, trans. by Takeuchi Yoshinori (Berkeley: University of California 
a cover up the Japanese culture that is now tainted by blood both criminal and innocent did not appeal to him. On the contrary, his is a genuine attempt at self-criticism that would put to question every inveterate belief one has held at the expense of openness to a reality that is neither pre-given nor statically perfect.

Tanabe is the leading intellectual that calls out to his people, but more so, to himself, for a repentance, for a philosophical remorse that leads to metanoia or zange. ${ }^{2}$ In this philosophical position, the self admits to itself with utter contriteness that its every effort at self-consciousness and all the results of these exertions, which are manifest in the institutions and all that legitimize these, will lead to nothing but further depravity and destruction; the self, then, has to genuinely repent and have an authentic conversion leading it to put its faith on the Other-Power. This philosophical position allows for the Self to transcend its metaphysical hubris, thereby breaking its created illusion of grandeur, which results from its self-consciousness, and finally, abandoning its concrete manifestations in its self-build systems and institutions; here, one has to abandon even its precious products, its prized self-knowledge.

Zange becomes Tanabe's response to the impossibility of a rigidly rational philosophy that is fueled by its traditional dogmatic categories; this becomes also a good starting point for a creative criticism - a movement that could possibly be stifled by our blind faith to dogmatic policies and institutions that we try to preserve for dear life precisely because we are averse to anything that will rattle our sedimented status quo. ${ }^{3}$ Zange opens the avenue for a philosophy that is no longer a philosophy of self-consciousness, for

Press, 1986) in the intellectual climate of post-war Japan, as it is one of the few works that gained sympathy from among critics who attack the Kyoto School Philosophers for their alleged complicity during the war.

2 The position of metanoetics or repentance that is purported by Tanabe is perhaps one of the strongest works that one way or the other proves and exemplifies the potency of the Eastern position of Absolute Nothingness as a philosophical stance through which Western tradition is read and evaluated. Heisig expresses this perceptibly by saying that the standpoint of Nothingness focuses not on objects - which has always been the focus of Western philosophy, most especially during the Modern Era-but begins from the reflection of the self upon itself allows for Eastern philosophy to rest "on a primarily psychological realization of the world akin to religious experience." Heisig, Foreword in Philosophy as Metanoetics, xix.

Metanoetics, therefore, as a potent philosophical position that transcends the traditional understanding of philosophy, a "nonphilosophical philosophy" as it were, is the very standpoint that longs for the critique and reflection of the self upon the self. Tanabe writes: "I call it a philosophy that is not a philosophy because, on the one hand, it has arisen from the vestiges of a philosophy I had cast away in despair, and on the other, it maintains the purpose of functioning as a reflection on what is ultimate and as a radical self-awareness, which are the goals proper to philosophy." Tanabe, Philosophy as Metanoetics, li.

3 Tanabe expresses this pointedly in the following: "In general, I have always been critical of abstract ideals like culturism and culture-worship, and I am especially reluctant to approve of the preset stress on 'culture' since I have no faith in its future... One step in the wrong direction, even one day's delay, may be enough to spell the total ruin of our land. Unless we all undertake the new way of zange, free ourselves from the evil institutions of the past, and collaborate in carrying out whatever changes are necessary in the social system, there is no possibility of reconstruction. The only course open to us at present is metanoetics, not culturism (my italics)." Tanabe, Ibid., lxi. 
philosophy's resurrection from the ashes of the Self that died to itself. This paper, then, is a reflection on Tanabe's suggestion on what we should or could do if rationality has become pathological, if thinking can no longer contain the irrational, and if at the demise of philosophy, nothing remains but the haunting gossamer of injustice's debris crying for recognition, demanding for an apology.

\section{Zange as Philosophy beyond Philosophy}

What hope is there left for us if philosophy, and its promised rationality, has abandoned us in our quest for meaning after an event that causes tremendous disruption to the very core of our being? What hope is there if the very culture that we trusted to deliver us from the clutches of evil and pain becomes the very tool that is used for the justification of a heinous crime that cannot really be even spoken without the reflex of a shudder, without an almost automatic hush? What hope is there when our systems and policies, the very results of our self-reflection and self-consciousness becomes more primordial, more important than us, becomes more real than us, the very people these institutions are supposed to serve? ${ }^{4}$ These are the questions that beset us if we try to seriously ponder on traditional and systematic philosophy's helplessness to give us the consolation we need when we are at a loss for answers, when we are confronted by the irrationality of injustice that takes the mask of loyalty to tradition and the institution that keeps it safe from the harm of criticism.

But the disconcerting sight of philosophy's mutilation and incapacity, and the frustrating ignorance that ensues from the ones who are supposed to know better, who are supposed to be ready to handle philosophy's devastating lack, leads Tanabe to the realization that his suffering is not only caused by seeing the suffering of his people; rather, it springs from the realization that on the one hand, he has a responsibility as a philosopher to point out the rashness of his country that has willingly participated in the war, but at the same time, he is equally restrained from acting precisely because of the knowledge that expressing one's ideas in a time of crisis may lead to a division among his people that would have produced greater damage than good. And in this tempestuous state, Tanabe arrives at something astonishing: in the impossibility of teaching and correcting others, he is lead to realize that he can only humbly confess and surrender to his weakness and in this surrender, he is able to view

${ }^{4}$ Levinas' insight on violence and war is almost similar: "But violence does not consist in injuring and annihilating persons as in interrupting their continuity, making them play roles in which they no longer recognize themselves, making them betray not only commitments but their own substance, making them carry out actions that will destroy every possibility of action. It establishes an order from which no one can keep his distance; nothing henceforth is exterior. War does not manifest exteriority and the other as other; it destroys the identity of the same." Emmanuel Levinas, Totality and Infinity: An Essay on Exteriority, trans. Alphonso Lingis (Pittsburgh: Duquesne University Press, 1969), 21. 
with humility his own inner self and explore the depths of his powerlessness and incompetence. ${ }^{5}$

This humble confession of powerlessness, this metanoia or zange becomes the new intellectual task for Tanabe that he has to pursue as best as he could, and his decision to pursue it led him to a "philosophy that is not philosophy," to a "philosophy that is seen as the self-realization of metanoetic consciousness." "This non-philosophical philosophy-one that is born out of the denial out of despair of the previous philosophy that could only be tenable if either the sage or the saint did it - maintains the radical function that leads to self-awareness; this awareness, which is reached via negativa, allows Tanabe to push for the standpoint of philosophical remorse that has conversion as its consequence. But this almost solitary stance hopes for a wider scope: it is not only Tanabe who is ignorant and weak; it is all of Japan, nay, it is all of us and all of us are responsible for the failure of our institutions, for the disgrace that now stains our systems with innocent blood, and for the weakness that convicts our silence which quietude only gives brighter light to our complicity. ${ }^{8}$

\section{From Contemplation to Conversion}

More than being an apologist, Tanabe, aware that he might be criticized by the other intellectuals during the efforts to recover from Japan's humiliating defeat and surrender, is strongly convinced that whatever motives he has for his confession of his weakness and whatever the motivation that fuels his repentance and conversion, the only way for him to proceed philosophically is via the way of metanoetics; whatever self-consciousness is hoped for, whatever wisdom is attained, it can only be so through metanoesis. Tanabe explains that metanoetics' significance lies in its philological denotation: it is beyond, thus, transcending the self that thinks, which ultimately means "a

5 Tanabe's turmoil has led him to a particular task that he has to pursue, and whether this task could be called philosophy or not does not really matter anymore; and the task that endeavors a very personal and individual criticism is this: "The only thing for me to do in the situation was to resign myself to my weakness, to examine my own inner self with humility, and to explore the depths of my powerlessness and lack of freedom." Tanabe, Philosophy as Metanoetics, 1.

6 Ibid.

7 Ibid.

8 Tanabe, with great poignancy stresses this in saying: "But in the strict sense we Japanese are all responsible for the failure and disgrace since we were unable to restrain the reckless ways of the government and the militarists. After those who are directly to be blamed for the disasters that befell Japan, the leaders in the world of social and political thought are most responsible. There is no excusing the standpoint of the innocent bystander so often adopted by members of the intelligentsia." Ibid., liv. Levinas' statement-“...I am responsible for the Other without waiting for reciprocity, were I to die for it. Reciprocity is his affair... It is I who support all... The I always has one responsibility more than all the others"-becomes more specified and meaningful here, for it renders the intellectuals more responsible than others, a position that is supposed to lead to the admission of fault not only by them, but eventually by all. See Emmanuel Levinas, Ethics and Infinity: Conversations with Philippe Nemo, trans. by Richard A. Cohen (Pittsburgh: Duquesne University Press, 1985), 99. 
transcending of metaphysical philosophy based on contemplation or intellectual intuition achieved by the use of reason." "This abandonment of hubristic metaphysics that could only be attained through the trust on the powers of reason to bring about self-awakening brings to fore the countenance of reason that is at the edge of its rationality; jiriki is no longer defensible.

The absolute disruption that is caused by the realization that I am a weak and an ignorant fool allows me to see myself as incapable of a metaphysical self-awakening, a standpoint that brings about immediate intellectual intuition only for the saints and the sages; as I am ignorant and weak, I can only surrender myself to the death to my self-power so that I could be reborn to the Absolute Nay of the Great Compassion's other-power. As I am weak and ignorant, I can only confess to the tenacity of my folly and hope that this confession could become a genuine avenue for conversion. But something more beautiful is inherent in this seemingly despairing confession of one's incapacity: "qange is a true self-surrender that consists not in a recalcitrant despair but in a submissive one, a despair in which we renounce all hope for and claim to justification;"10 and in this submission, the self that has been denied is once again affirmed, in this self-surrender, the abundant gift of grace "of a resurrected self that brings with it the joy of a regenerated life"11 is lovingly bestowed.

The self that commits itself to zange realizes that it has to die to itself in order for it to be resurrected; it understands that it has to abide to absolute nothingness, to the Great-Nay-qua-Great-Compassion, and only in the corollary selflessness of this great abiding, of this grace-filled death would the Self realize that the only philosophy possible for it to undertake is the path of zange that has already been paved by the Great Compassion's other-power. ${ }^{12}$ The absolute critique of the self that begins with the steadfast belief in its capacity for contemplation cannot really go further than the realization of its powerlessness and folly, and in this awakening to one's weakness, the Self comprehends also that it cannot anymore put its trust to the institutions and systems that are the prized products of its self-consciousness, but more so, it cannot go on protecting these out of fear of the destruction of its culture; for what culture is there still to protect if the price one has to pay for its

\footnotetext{
${ }^{9}$ Tanabe, Philosophy as Metanoetics, 2.

10 Ibid., 5.

11 Ibid., 6.

12 Tanabe claims that even Kant's critical philosophy if pushed further would find that its perspective is not enough to provide the foundation for an autonomous reason. "Reason endowed with the capacity for self-criticism cannot evade the ultimate predicament of the antinomies of practical reason, since it is caught up in original sin stemming from basic human finitude... I would conclude, therefore, that metanoetics is not merely one possible way among a variety of philosophical ways: it is the only way, the ineluctable way. It is the ultimate conclusion to which the critique of reason drives us." Ibid., 20. Metanoetics becomes the ultimate result when the critique of reason is made into an absolute critique. Self-awareness could only end in the realization that $I$ am not enough and that $I$ need the help of the Other-Power, of the grace
} that is initially bestowed. 
proliferation is the truth, one's soul and the sacrifice of the many others who were victims of policies and rules?

\section{Brotherhood through Genso}

For Tanabe, the need for metanoesis for the dwindling situation of his country after the war is a matter of great urgency, but the Japanese government's desire to cling onto the institutions of the past regardless of their defectiveness and evil becomes a lot easier resort than the confession of one's sins and the authentic heartfelt resolution and recreation of systems tainted by selfishness and dogmatism. Metanoesis is the only way a community could go if it wants to remove itself from the apparent degradation and depravity as it is continuously encompassed by the evils of dogmatic institutions and uncreative policies. $^{13}$ But the situation of Tanabe is not indigenous to his time and his country. How many times have we become frustrated precisely because our own institutions have favored the letter of the law instead of its spirit? How many times have we seen our potentials curtailed and amputated precisely because policies would not agree to the truth that is obfuscated by incoherent policies? Our institutions too need to take the path of zange!

But similar to Tanabe, I am also a weak and an ignorant fool and I cannot call others to undergo metanoesis precisely because I have to undergo it myself. I have to realize incessantly my weakness and depravity, I have to perpetually die to myself so that I could have hope for forgiveness, so that I could hope to forgive, so that I could be resurrected in the other-power's Compassion and be a selfless mediation for other's conversion. But none of these is attainable through my own power for I am already saved by the meritfilled grace earned for me by the sacrifices of Darmakara during his Boddhisattvaship. $^{14}$ But even this assurance is not enough, for my powerlessness blocks me from the realization of this marvelous gift. In the meantime, I have to constantly repent for my weakness and ignorance hoping, like Shinran of old, like Tanabe as well, that others would trudge the path of metanoia, of conversion. ${ }^{15}$ Nevertheless, this does not cause a dampened spirit

13 Of course, not all institutions are evil, nay, all institutions are neither good nor evil; Ricoeur states this emphatically in his article, "The Socius and the Neighbor" in saying that institutions or to be more exact, "technical procedures" have the "innocence of the machine." Paul Ricoeur, "The Socius and the Neighbor," in History and Truth, trans. Charles A. Kelbley, Evanston: Northwestern University Press. 1965), 107. But one has to be careful, for this innocence could assume the face of the Lawyers whom Christ rebuked for weighing the people down without them bothering to lift a finger to help [Luke 11:46].

${ }^{14}$ See The Larger Sukhavati-vyuha in Buddhist Mahayana Texts, trans. by Max Muller (New York: Bover Publications, Inc., 1969), 10-11, where the extraordinary practice for the accumulation of merits to be bestowed to all suffering beings in the world of endless birth and death done by Dharmakara is described.

15 The following is Shinran's confession, which resonates with the recurrent avowal of Tanabe: "I now truly realize! How wretched I am! Ran the stupid bald-headed one, deeply submerged in the wide ocean of desires and cravings, confusingly lost among the huge mountains of worldly fame and interests, has no aspirations for being counted among the elite of 
for while I cannot anymore take pride on my own accomplishments, I am guided by some who are stronger than I.

The genso movement, this compassionate going back for the benefit of others, gives hope for ignorant beings as I. I do not have any hope at arriving at an immediate self-knowledge; I do not have any hope for saving myself; rather, I have to abide to Absolute Nothingness' compassion and from the resurrection that is engendered in this humbling death, I would, then, have a little hope to effect change in others. But as it is, I am guided by the ones who are stronger than I, by the ones who came before me and through their example, I become involved not in mere contemplation, aloof and solitary, but in a brotherhood that lifts me from the painful cycle of samsara. Through this communal involvement, I participate in the effort of the firstborn to bring all beings to the remote father, to the shrouded mother, so that all could dwell in the Land where pain is no more, where suffering is no longer. ${ }^{16}$ But this requires an incessant distrust in the belief that our life is a mere human project as this dogmatizes and hypostatizes the world of our own creation, of our own limited self-awakening.

\section{Epilogue}

The arrogance that results from our belief in our progress as a human civilization and our pride for the accomplishments of self-consciousness that are concretely manifested in our institutions and systems, are always disrupted at the occasion of irrationality and injustice, at the sight of suffering when institutions are supposed to alleviate it. In these times it becomes clear at the horizon of our consciousness the impending doom that threatens these prized possessions, and more often than not, our reflex stance is always to defend these institutions, these systems by holding on to every letter, every number, every ball of our institutional policies, notwithstanding the hurt lives, crushed dreams and amputated potentialities of the victims of this tenacious onslaught.

But our dogmatic efforts at preservation will break like any human citadel, and at the destruction of our protective walls, we will be left with the realization that we are ignorant and foolish, that we are weak, and in our powerlessness we will arrive at the stance of metanoesis, the stance that arises from the very depths of our being, the stance that promises that efforts will be exerted to ensure that the same injustices will not be repeated, and the pathologies are somehow healed if not totally cured. But in the event that there is not yet a "We" precisely because the "Others" still trust their matrices and the "Wise" is still busy making the system work for them, then at least, through the guidance of people more humble than I, I have already started

the definitely assured group and feels no pleasure in approaching the really true experience. How deplorable! How heart-rending!" Gutoku Shaku Shinran, The Kyogyoshinsho: The Collection of Passages Expounding the True Teaching, Living, Faith, and Realizing of the Pure Land, trans. by Daisetz Teitaro Suzuki (Kyoto: Shinshu Otaniha, 1973), 140.

16 Tanabe, Philosophy as Metanoetics, 295. 
beating my chest for the continuous proliferation of ghosts crying for an apology.

Department of Philosophy, University of Santo Tomas, Philippines

\section{References}

Heisig, James, Philosophers of Nothingness: An Essay on the Kyoto School (Honolulu: University of Hawaii Press, 2001).

Levinas, Emmanuel, Ethics and Infinity: Conversations with Philippe Nemo, trans. by Richard A. Cohen (Pittsburgh: Duquesne University Press, 1985).

Totality and Infinity: An Essay on Exteriority, trans. Alphonso Lingis (Pittsburgh: Duquesne University Press, 1969).

Ricoeur, Paul, "The Socius and the Neighbor," in History and Truth, trans. Charles A. Kelbley, Evanston: Northwestern University Press. 1965).

Shinran, Gutoku Shaku, The Kyogyoshinsho: The Collection of Passages Expounding the True Teaching, Living, Faith, and Realizing of the Pure Land, trans. by Daisetz Teitaro Suzuki (Kyoto: Shinshu Otaniha, 1973).

Tanabe, Hajime, Philosophy of Metanoetics, trans. by Takeuchi Yoshinori (Berkeley: University of California Press, 1986).

The Larger Sukhavati-vyuha in Buddhist Mahayana Texts, trans. by Max Muller (New York: Bover Publications, Inc., 1969). 